\title{
Observation of Antioxidants Activity using NMR Relaxation Measurements
}

\author{
D. Wierzuchowska ${ }^{a, *}$, M. WiteK ${ }^{b}$ AND B. Blicharska ${ }^{c}$ \\ ${ }^{a}$ Institute of Physics, Pedagogical University, Podchorążych 2, 30-084 Kraków, Poland \\ ${ }^{b}$ Faculty of Food Technology, University of Agriculture in Krakow, Balicka 122, 30-149 Kraków, Poland \\ ${ }^{c}$ Institute of Physics, Jagiellonian University, S. Łojasiewicza 11, 30-348 Kraków, Poland
}

\begin{abstract}
Formation of free radicals in biological solutions leads to the changes in water protons relaxation times. Therefore, NMR relaxation measurements were used to investigate kinetics of oxidation processes induced by the addition, in low amounts, of hydrogen peroxide $\left(\mathrm{H}_{2} \mathrm{O}_{2}\right)$ to aqueous protein solution and to blood serum. The measured relaxation times were not stable over time because of the progressive formation of free radicals and their damaging action to the protein structure. The addition of antioxidants (ascorbic acid, gallic acid etc.) changed the relaxation time courses due to free radical scavenging. Similar time courses, thus anti-oxidant actions, were observed in various blood serum without antioxidant additive. Moreover, the observed kinetics of spin-lattice relaxation time $\left(T_{1}\right)$ depended on several factors, such as: structure and concentration of protein solutions and activity and concentration of the added antioxidants.
\end{abstract}

DOI: 10.12693/APhysPolA.133.289

PACS/topics: 76.60.-k, 76.90.+d, 76.30.Rn

\section{Introduction}

Among biologists and pharmacists there is growing interest in the oxidation of small molecules, peptides and protein in the presence of hydrogen peroxide. Oxidative stress is related to the onset of many diseases such as inflammatory and cardiovascular diseases, cancer, diabetes, autism, cataracts, and accelerating aging. Up to now, oxidative reactions and total antioxidant capacity of species have been investigated by various methods and analytical tools i.e. spectrometry, electroanalytical methods and chromatography [1]. The typical, spectrophotometric methods involved measurements of absorbance at given wavelength, after the reduction of metal ions of lower degree of oxidation by given antioxidant (FRAP method) or sweeping up of stable, free radicals (ABTS and $\mathrm{DPPH}$ ).

In this work, we applied the NMR relaxation method to observe the oxidation processes induced by the addition of hydrogen peroxide to biological solutions as well as antioxidant action of some of the best-known antioxidants. The oxidation processes induce changes in relaxation times, since the free radicals formed in the solutions are paramagnetic and may also damage the protein structure. The character of these time courses is very sensitive to the concentrations of hydrogen peroxide and protein, and to the type of antioxidant compounds present in solutions.

\section{Materials and methods}

Lyophilized and powdered egg white albumin (EWA, MW 44287 Da, Polskie Odczynniki Chemiczne, Poland)

\footnotetext{
*corresponding author; e-mail: dw7@onet.eu
}

was dissolved in distilled water at concentration ranging from $4 \%$ to $20 \%$ by weight, while lyophilized rabbit serum (RSA, Biomed Krakow, Poland) in distilled water according to the producer's recommendation.

Fresh human and dog blood serum, treated with citric acids, being an excess material after routine investigation, was obtained from the diagnostic stations.

The antioxidants applied were ascorbic acid (AA, vitamin C, Polskie Odczynniki Chemiczne, POCH Poland) and gallic acid (GA, Fluka Chemika Switzerland), which were used as saturated water solutions at the concentrations of $17 \%(\mathrm{w} / \mathrm{w})$ and $1 \%(\mathrm{w} / \mathrm{w})$, respectively $[2,3]$.

In order to induce the oxidative process, the $3 \%$ hydrogen peroxide (purchased from pharmacy) was added and mixed with protein solution or serum immediately before measurements.

Proton NMR relaxation time $T_{1}$ was measured using a Minispec Bruker spectrometer, operating at $1.5 \mathrm{~T}$ $(60 \mathrm{MHz})$ at room temperature $\left(23^{\circ} \mathrm{C}\right)$, using an inversion recovery (IR) method. The values of $\tau$ at IR sequence ranged from 50 to $20000 \mathrm{~ms}$. The $90^{\circ}$ pulse length was $1.3 \mu \mathrm{s}$, and the repetition time between scans was between 10 and $15 \mathrm{~s}$.

Data were analyzed using a mono-exponential function by means of the standard Bruker procedure. Measurements errors were less than $2 \%$.

\section{Results and discussion}

Figure 1 shows the $T_{1}$ time courses in $7 \%$ aqueous EWA solutions after adding of $\mathrm{H}_{2} \mathrm{O}_{2}$ in a ratio of $1: 10$ to a solution without any antioxidant and with AA or GA additive. The initial $T_{1}$ values for these solutions were 1995,1850 , and $1895 \mathrm{~ms}$, respectively. Immediately after adding $\mathrm{H}_{2} \mathrm{O}_{2}$, the $T_{1}$ value decayed exponentially and reached a plateau after $c a .2500 \mathrm{~s}$ in the samples without antioxidant. The mono-exponential model was fitted to time courses according to Eq. (1): 


$$
T_{1}(t)=T_{1 p}+A_{0} \exp \left(-\frac{t}{t_{d}}\right),
$$

where $T_{1 p}, A_{0}$ and $t_{d}$ are fitted parameters that were shown in Table I. The $t_{d}$ value decreased with an increase in protein concentration up to $10 \%$ and remained unchanged, within an experimental error, for $20 \%$ concentration. It may be due to the observed change in the structure of solution at critical concentration $12.8 \%$ and a decrease of free water that interact with $\mathrm{H}_{2} \mathrm{O}_{2}$ [4].

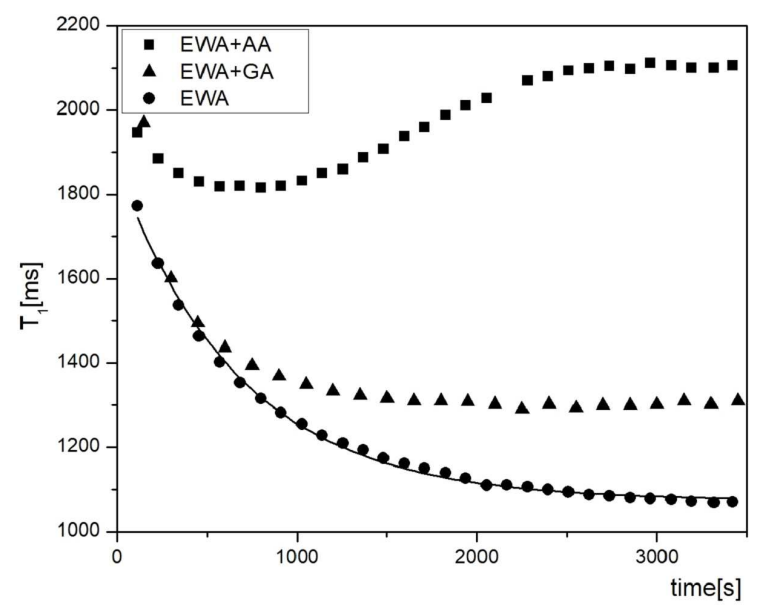

Fig. 1. The time courses of $T_{1}$ relaxation time after adding $3 \% \mathrm{H}_{2} \mathrm{O}_{2}$ in a ratio of $1: 10$ to $7 \%(\mathrm{w} / \mathrm{w})$ egg white aqueous solution without any antioxidants (EWA), with ascorbic acid (EWA +AA) and with gallic acid $(\mathrm{EWA}+\mathrm{GA})$. The initial values of $T_{1}$ were $1995 \mathrm{~ms}$ (EWA), $1850 \mathrm{~ms}$ (EWA+AA) and $1895 \mathrm{~ms}$ $($ EWA $+\mathrm{GA})$. The solid line shows the fit according to Eq. (1).

TABLE I

Values of parameters obtained from fitting monoexponential model according to Eq. (1) to time courses of $T_{1}$ for different concentration of EWA solutions after adding $\mathrm{H}_{2} \mathrm{O}_{2}$ in a ratio of $1: 10$.

\begin{tabular}{c|c|c|c}
\hline \hline EWA conc. $[\mathrm{g} / 100 \mathrm{~g}]$ & $T_{1 p}[\mathrm{~ms}]$ & $A_{0}[\mathrm{~ms}]$ & $t_{d}[\mathrm{~s}]$ \\
\hline 4 & $1560 \pm 1$ & $702 \pm 11$ & $948 \pm 53$ \\
7 & $1074 \pm 5$ & $793 \pm 10$ & $682 \pm 18$ \\
10 & $1260 \pm 3$ & $711 \pm 13$ & $333 \pm 90$ \\
20 & $1190 \pm 4$ & $756 \pm 21$ & $344 \pm 14$
\end{tabular}

In the solutions with added antioxidants, $T_{1}$ values reached the minimum at about $1000 \mathrm{~s}$ and then started to grow. The increase observed in relaxation time values revealed that the free radical effect was disappearing due to scavenging activity of the antioxidants used [5]. The same phenomenon was observed in the bovine serum albumin solutions [6]. The increase in $T_{1}$ was significant in protein solutions with $\mathrm{AA}$, while in the samples with GA was weaker in a time course of experiment. The addition of GA to the protein solution containing $\mathrm{H}_{2} \mathrm{O}_{2}$ only decreased the extent of $T_{1}$ changes. This suggests that either AA is a stronger antioxidant than the GA or that the concentration of GA is too low to scavenge free radicals in the solution [7]. Indeed, the applied GA concentration was only $1 \%(\mathrm{w} / \mathrm{w})$, but this is the maximal achievable concentration in water solution at room temperature [3]. The $T_{1}$ dependence on antioxidant concentration has been already studied in the previous work [5] for AA and glutathione additives, the recovery of $T_{1}$ relaxation time was found to be more effective at higher concentrations of these antioxidants.

In any case, the observed differences in time courses showed that the NMR relaxation measurements may be sensitive to kinetics of oxidation processes and antioxidant action.

Similar character of time decay of chemical oxidation after adding $\mathrm{H}_{2} \mathrm{O}_{2}$ was observed on "advanced oxidation processes" (AOP) research, which was conducted by various methods. Since 1987, the AOP approach has been used in purification treatment as the technique using $\mathrm{H}_{2} \mathrm{O}_{2}$ enhanced by UV radiation to eliminate the majority of organic and inorganic contaminants in water [8].

Oxidation reactions are of prime importance not only in industry, but also in nature to understand, for example, marine environment, in which various Red Sea corals release $\mathrm{H}_{2} \mathrm{O}_{2}$ and antioxidants [9].

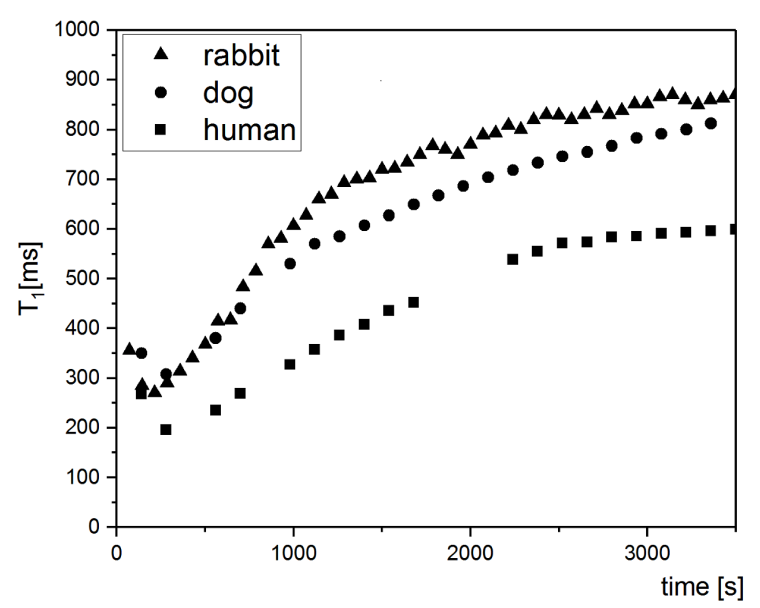

Fig. 2. The time courses of $T_{1}$ relaxation time after adding $3 \% \mathrm{H}_{2} \mathrm{O}_{2}$ in a ratio of 1:10 to blood serum: human, dog, and rabbit. The initial values of $T_{1}: 1770 \mathrm{~ms}$ (human serum), $1636 \mathrm{~ms}$ (dog serum), $1690 \mathrm{~ms}$ (rabbit serum).

Free radicals scavenging can also be seen in Fig. 2, which illustrates $T_{1}$ time courses after adding $\mathrm{H}_{2} \mathrm{O}_{2}$ to fresh human and dog blood serum as well as to rabbit serum solutions. The initial $T_{1}$ relaxation values for native samples were $1770 \mathrm{~ms}$ (human) and $1636 \mathrm{~ms}$ (dog) and for the rabbit serum solution the initial $T_{1}$ value was $1690 \mathrm{~ms}$. After adding small amounts of $\mathrm{H}_{2} \mathrm{O}_{2}$ (at a ratio of 1:10), they dropped significantly to 196,308 , and $271 \mathrm{~ms}$, respectively (Fig. 2). All curves showed the same characteristics: short decays at the beginning, followed by an increase until the plateau was reached. This behavior is quite similar to the results obtained for the aqueous protein solution with the added antioxidant (Fig. 1). 


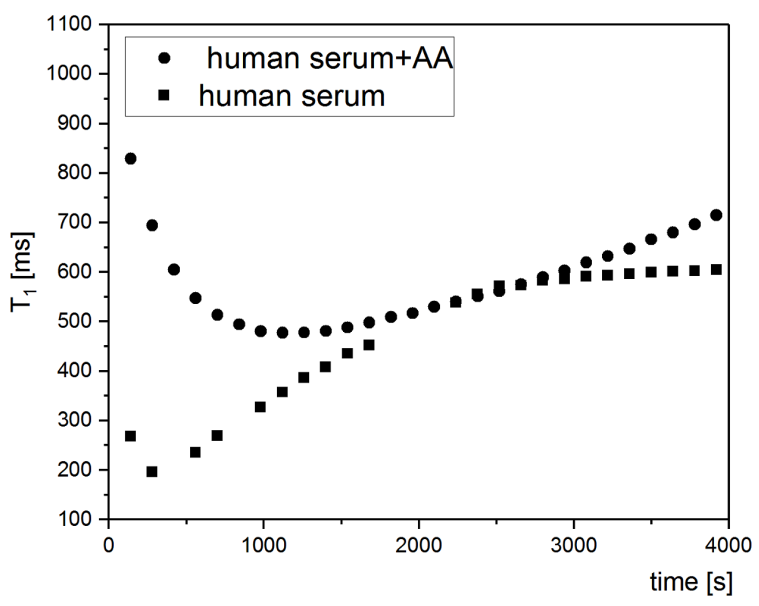

Fig. 3. The time courses of $T_{1}$ relaxation time after adding $3 \% \mathrm{H}_{2} \mathrm{O}_{2}$ in a ratio of 1:10 to human blood serum and to human blood serum with AA.

The difference was observed only at the beginning of time courses; the drop as well as the following increase in the value of spin-lattice relaxation time was faster in comparison to egg white albumin solutions (Fig. 1). Anyway, this may suggest that antioxidant species occur in native blood serum. Such antioxidant activity may derive from low molecular weight proteins or peptides occurring in serum [10]. Moreover, the addition of AA to serum sample substantially enhanced the $T_{1}$ changes at the beginning of the observation, following rise as well as final effect, depending on antioxidant content (Fig. 3) [5].

\section{Conclusions}

The presented results showed that the kinetics of oxidation processes and antioxidant action of some species may be directly observed by time-resolved measurements of NMR relaxation times. The exposure of protein solution and blood serum to reactive species $\left(\mathrm{H}_{2} \mathrm{O}_{2}\right)$ leads to the formation of free radicals and structure damages. This process may be seen as mono-exponential decay of $T_{1}$ in the aqueous protein solution without any antioxidant after adding $\mathrm{H}_{2} \mathrm{O}_{2}$ and the time constant of $T_{1}$ decay was shorter for a higher concentration of proteins. When antioxidants were added or there were endogenous antioxidants in samples, the character of these time courses in such solutions was no more exponential. The $T_{1}$ value tended to increase in time of observation in all studied samples. This trend strongly depended on the type of protein solution (e.g., egg white albumins and human and animals serums), and antioxidants' activity and concentration (ascorbic acid versus gallic acid). Thus, it may be concluded that applying the NMR relaxation method and additional analysis of results by appropriate mathematical approximation, can be helpful in studying processes of oxidation and antioxidant action. Because of non-invasiveness, this NMR relaxation approach can be used in any case of biological materials.

\section{References}

[1] K. Rahman, Clin. Interv. Aging 2, 219 (2007).

[2] A. Shalmashi, A. Eliassi, J. Chem. Eng. Data 53, 1332 (2008).

[3] A. Daneshfar, H.G. Ghaziaskar, N. Homayoun, J. Chem. Eng. Data 53, 776 (2008).

[4] D. Wierzuchowska, B. Blicharska, Acta Phys. Pol. A 125, 907 (2014).

[5] L.W. Skorski, B. Solnica, B. Blicharska, J. Lab. Diagnost. 47, 85 (2011).

[6] D. Wierzuchowska, L.W. Skorski, B. Blicharska, Acta Phys. Pol. A 129, 226 (2016).

[7] G.-Ch. Yen, P.-D. Duh, H.-L. Tsai, Food Chem. 79, 307 (2002).

[8] J. Wąsowski, A. Piotrowska, Ochrona Środowiska 2, 27 (2002), (in Polish).

[9] R. Armoza-Zvuloni, Y. Shaked, Biogeosciences 11, 4587 (2014).

[10] M. Habdous, B. Herbeth, M. Vincent-Viry, J.V. Lamont, P.S. Fitzgerald, S. Visvikis, G. Siest, Clin. Chem. Lab. Med. 41, 209 (2003). 